\title{
Comparative evaluation of menstrual patterns and hormonal profiles in normal and abnormal perimenopause
}

\author{
Harshiba Kaur $^{1 *}$, Neerja Goel ${ }^{2}$ \\ ${ }^{1}$ Department of Obstetrics and Gynecology, UCMS and GTB Hospital, Delhi, India \\ ${ }^{2}$ Department of Obstetrics and Gynecology, Sharda Hospital, Greater Noida, Uttar Pradesh, India
}

Received: 19 March 2019

Revised: 04 August 2019

Accepted: 08 August 2019

*Correspondence:

Dr. Harshiba Kaur,

E-mail: harshiba@hotmail.com

Copyright: ( $)$ the author(s), publisher and licensee Medip Academy. This is an open-access article distributed under the terms of the Creative Commons Attribution Non-Commercial License, which permits unrestricted non-commercial use, distribution, and reproduction in any medium, provided the original work is properly cited.

\begin{abstract}
Background: Currently there is only one marker to objectively establish perimenopause ie menstrual irregularities. Due to the wide variation in hormones like LH, FSH, estradiol, they become unreliable in predicting approaching menopause. This study was conducted to study and compare the patterns of LH, FSH and Estradiol in normal and abnormal perimenopause using the Stages of Reproductive Ageing Workshop (STRAW) criteria.

Methods: A comparative evaluation was done after enrolling 200 patients out of which 100 women were in normal perimenopause (early-25 and late perimenopause-75, depending upon menstrual characteristics as defined by STRAW criteria) and 100 having AUB. Sociodemographic data, presence of menopausal symptoms were recorded. S. LH, S.FSH and S. estradiol we determined by adapted solid phase direct sandwich ELISA.

Results: FSH was in menopausal ranges (>20IU/L) in early and late perimenopause. LH and FSH in women with AUB ranged from pre to post menopausal ranges. There was significant difference in LH and FSH between normal perimenopause and abnormal uterine bleeding. Estradiol levels showed a significant difference between late perimenopause and AUB $\mathrm{p}=0.015$.

Conclusions: This study shows that there is a progressive incremental trend in FSH and LH and decremental trend in Estradiol from early to late perimenopause due to decrease in ovarian follicular reserve, although the difference is not significant. Clinical symptoms present in $50 \%$ of late perimenopausal women showed that besides menstrual characteristics we can correlate these menopausal symptoms with raised FSH and low Estradiol. These women can be picked up and preventive therapy may be provided.
\end{abstract}

Keywords: E2- Estradiol, Enzyme linked immunosorbant assay, Endometrial thickness, Follicular stimulating hormone, Luteinising hormone, Stages of reproductive ageing workshop

\section{INTRODUCTION}

Years before menopause that encompass the change from normal ovulatory cycles to cessation of menses and 12 months thereafter are known as the perimenopausal years. Perimenopause is defined as the period beginning with the first clinical sign of approaching menopause and ending 1 year after the final menstrual period. ${ }^{1,2}$ During this age various clinical, biological and endocrinological changes occur. The average age of onset of perimenopause is $43-45$ years and average duration is 5-8 years. ${ }^{3}$ Perimenopausal period is marked by variability of hormone secretion. The clinical response to this imbalance is depicted by menstrual irregularity, vasomotor symptoms, psychological symptoms and sexual dysfunction. Fluctuating estradiol levels give rise 
to symptoms of estrogen excess namely menorrhagia, migraine, nausea and breast tenderness and other symptoms like urogenital atrophy and vasomotor symptoms due to estrogen deficiency.

Although the hormonal features of perimenopause have still not been fully elucidated, perimenopause occurs when the primordial follicle count falls to around $100{ }^{4}$ Estrogen deficiencies due to falling follicular reserve causes negative feedback and rise in Follicle Stimulating Hormone (FSH). Lack of Inhibin released by the granulosa cells of antral/dominant follicle, further raises FSH. Anovulatory cycles show marked increase in FSH and LH with low estradiol.

\begin{tabular}{|c|c|c|c|c|c|c|c|c|c|}
\hline Mena & rche & & & & & FMF & (0) & & \\
\hline Stage & -5 & -4 & $-3 b$ & $-3 a$ & -2 & -1 & $+1 \mathrm{a}+1 \mathrm{~b}$ & $+1 c$ & +2 \\
\hline \multirow[t]{3}{*}{ Terminology } & \multicolumn{4}{|c|}{ REPRODUCTIVE } & \multicolumn{2}{|c|}{$\begin{array}{l}\text { MENOPAUSAL } \\
\text { TRANSITION }\end{array}$} & \multicolumn{3}{|c|}{ POSTMENOPAUSE } \\
\hline & Early & Peak & \multicolumn{2}{|l|}{ Late } & Early & Late & \multicolumn{2}{|l|}{ Early } & Late \\
\hline & & & & & \multicolumn{4}{|c|}{ Perimenopause } & \\
\hline Duration & \multicolumn{4}{|c|}{ variable } & variable & $1-3$ years & $\begin{array}{c}2 \text { years } \\
(1+1)\end{array}$ & $3-6$ years & $\begin{array}{l}\text { Remaining } \\
\text { lifespan }\end{array}$ \\
\hline \multicolumn{10}{|c|}{ PRINCIPAL CRITERIA } \\
\hline $\begin{array}{l}\text { Menstrual } \\
\text { Cycle }\end{array}$ & $\begin{array}{l}\text { Variable } \\
\text { to regular }\end{array}$ & Regular & Regular & $\begin{array}{l}\text { Subtle } \\
\text { changes in } \\
\text { Flow/ } \\
\text { Length }\end{array}$ & \begin{tabular}{|l|} 
Variable \\
Length \\
Persistent \\
27 -day \\
difference in \\
length of \\
consecutive \\
cycles \\
\end{tabular} & $\begin{array}{l}\text { Interval of } \\
\text { amenorrhea } \\
\text { of }>=60 \\
\text { days }\end{array}$ & & & \\
\hline \multicolumn{10}{|c|}{ SUPPORTIVE CRITERIA } \\
\hline $\begin{array}{l}\text { Endocrine } \\
\text { FSH } \\
\text { AMH } \\
\text { Inhibin B }\end{array}$ & & & $\begin{array}{l}\text { Low } \\
\text { Low }\end{array}$ & $\begin{array}{l}\text { Variable } \\
\text { Low } \\
\text { Low }\end{array}$ & $\begin{array}{l}\uparrow \text { Variable } \\
\text { Low } \\
\text { Low }\end{array}$ & $\begin{array}{l}\uparrow_{\text {Low }}>25 \mathrm{IU} / \mathrm{L} \cdot . \\
\text { Low }\end{array}$ & $\begin{array}{l}\uparrow \text { Variable } \\
\text { Low } \\
\text { Low }\end{array}$ & $\begin{array}{l}\text { Stabilizes } \\
\text { Very Low } \\
\text { Very Low }\end{array}$ & \\
\hline $\begin{array}{l}\text { Antral Follide } \\
\text { Count }\end{array}$ & & & Low & Low & Low & Low & Very Low & Very Low & \\
\hline \multicolumn{10}{|c|}{ DESCRIPTIVE CHARACTERISTICS } \\
\hline Symptoms & & & & & & $\begin{array}{l}\text { Vasomotor } \\
\text { symptoms } \\
\text { Likely }\end{array}$ & $\begin{array}{l}\text { Vasomotor } \\
\text { symptoms } \\
\text { Most Likely }\end{array}$ & & \begin{tabular}{l|} 
Increasing \\
symptoms of \\
urogenital atrophy
\end{tabular} \\
\hline
\end{tabular}

Figure 1: The stages of reproductive aging workshop + 10 staging system for reproductive aging in women.

In 2001 and later in 2011 STRAW (Stages of Reproductive Ageing Workshop) proposed a nomenclature widely accepted according to which the entire life of a woman is divided into various stages depending upon ovarian ageing..$^{5}$ It has menstrual and qualitative hormonal criteria to define each stage.

Perimenopause or menopausal transition is divided into early (-2) and late (-1) stages depending on menstrual pattern. During early perimenopause there is a persistent difference of 7 days or more but less than 60 days in the length of consecutive cycles, whereas in late perimenopause there is amenorrhea of more than 60 days but less than 12 months. Along with this there is presence or absence of clinical or endocrinological changes.

Endocrinological changes during perimenopause occur due to the fall in ovarian follicles thereby resulting in lower inhibin levels. During earlier phase FSH rises but estradiol is preserved hence women continue to cycle regularly. Further fall in follicles cause anovulatory cycles and women enter into stage -2 or -1 . During this phase there is low estradiol, low inhibin and high FSH mimicking postmenopause. There may be fluctuating estradiol levels and low FSH which may cause LH trigger with delayed ovulation. Eventually with the end of this phase menopause sets in.

With fluctuating estradiol levels endometrial build is also variable. Short and long cycles occur. Short cycles exhibit a normal pattern with high FSH levels and low or sometimes high estradiol levels, whereas long cycles have variable gonadotropin levels with low levels of estrogen mostly. ${ }^{6}$

Clinical features of perimenopause can last for years. They occur due to the unpredictability and variability of hormone secretion. These include vasomotor symptoms, psychological symptoms, menstrual irregularities and sexual dysfunction. Women are more likely to seek medical help in their perimenopausal years than in pre or post menopause. No accurate predictor exists to mark the 
onset of perimenopause except menstrual irregularity. ${ }^{7}$ The two items that best define the inception of perimenopause were found to be 3-11 months of amenorrhea and increased menstrual irregularity for those without amenorrhea. This definition can be easily used in large epidemiological studies.

Less attention has been paid to patients with abnormal and heavy bleeding during perimenopause. These women need to have a thorough diagnostic evaluation. If AUB occurs for more than 3 month it could indicate local pathologies like leiomyoma/adenomyosis or endometrial hyperplasia/malignancy. About a quarter of these women may need medical/surgical assistance.

Hormonal genesis of perimenopausal AUB has been postulated by luteal out of phase (LOOP) phenomenon. In this phenomenon there are high follicular phase FSH levels with in turn recruit a second follicle in the luteal phase. LOOP cycles were found to have higher early cycle FSH, lower early cycle inhibin and lower luteal phase progesterone. ${ }^{8}$ Etiology of perimenopausal AUB may be multifactorial ie anovulatory

Since little work has been done on determining hormonal levels in perimenopausaul AUB, this study was taken up to define and compare the hormonal levels of LH, FSH and Estradiol in normal and abnormal perimenopause.

Objective of this study was to study and compare the levels of FSH, LH and estradiol in normal and abnormal perimenopause.

\section{METHODS}

A comparative evaluation was carried out on 200 patients attending OPD in Department of Obstetrics and Gynaecology in GTB hospital, Delhi from October 2014 to April 2016. Out of the 200 hundred patients were grouped as normal perimenopause, 25 in early perimenopause and 75 in late perimenopause, as defined by the STRAW criteria. Hundred patients of abnormal uterine bleeding of perimenopausal age were taken.

The inclusion criteria for both groups was age $>40$ years. For normal perimenopause as defined above, patients with consecutive menstrual cycle differing in length $>7$ days were taken as early perimenopause and patients with amenorrhea $>60$ days were taken as late perimenopause. For abnormal perimenopause any other pattern of abnormal menstrual bleeding like menorrhagia, metrorrhagia or polymenorrhea, polymenorrhagia and metropathica hemorrhagica were taken. Exclusion criteria were postmenopausal bleeding, pregnancy, lactation, history of DM2 hypo/hyperthyroidism and history of intake of hormonal preparations.

A complete history of the patient was taken including demographic variables, presence or absence of menopausal symptoms like vasomotor changes etc. besides menstrual, obstetric and past history. One time blood samples were obtained to measure S.FSH, S.LH, S. Estradiol at the time of OPD visit, as most of the patients had either irregular bleeding or heavy bleeding day 2 sampling could not be done.

An adapted solid phase direct sandwich ELISA test was the principal of the ELISA kits used to measure the levels of these hormones. A transvaginal USG was done for all patients using endoluminal probes of 5-9 $\mathrm{MHz}$. Endometrial thickness was measured for all patients. Patients with ET>8 were followed up with endometrial sampling.

Since levels of FSH weren't normally distributed in perimenopause unpaired t-test (with appropriate transformation to make them normal) was applied to find significant difference in hormonal levels between normal and abnormal perimenopause. To study effects of demographic variables on bleeding patterns in perimenopause chi square test was used.

\section{RESULTS}

In this study the mean age of women in early perimenopause was $42.6 \pm 3.5$ years and in alte pweimenopause was a $43.7 \pm 4$ year. The mean age of women with abnormal perimenopausal bleeding was $44.4 \pm 4$ years. Majority of women in all groups were between $40-45$ years $(88 \%, 73 \%, 77 \%$ in early, late and abnormal perimenopause respectively).

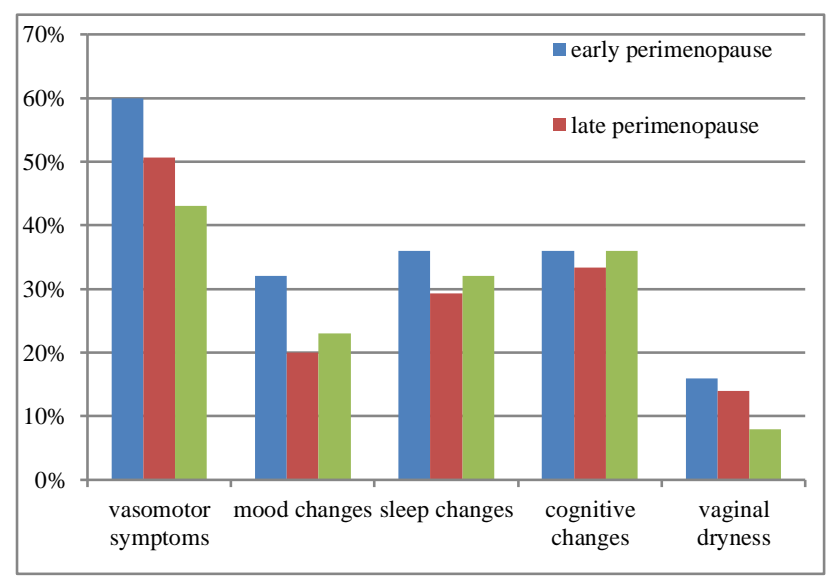

Figure 2: Frequency of symptoms in normal perimenopause (early and late) and abnormal perimenopause.

Maximum women belonged to the lower and upper middle socio economic status (32\% each) in early perimenopause. In late and abnormal perimenopause maximum women belonged to the lower socioeconomic group (46.6\% and $42 \%$ respectively).

Most women in early and late perimenopause group fell in the obese range $\left(\mathrm{BMI}>25 \mathrm{~kg} / \mathrm{m}^{2}\right), 56 \%$ and $58.6 \%$ respectively. According to consensus definitions for 
Asian Indians for body mass index and abdominal obesity normal BMI: $18.0-22.9 \mathrm{~kg} / \mathrm{m}^{2}$, overweight:23.0$24.9 \mathrm{~kg} / \mathrm{m}^{2}$, obesity: $>25 \mathrm{~kg} / \mathrm{m}^{2}$ (64). Mean BMI for normal perimenopause was $25.5 \pm 3.8 \mathrm{~kg} / \mathrm{m}^{2}$ and for abnormal perimenopause was $24.9 \pm 3.9 \mathrm{~kg} / \mathrm{m}^{2}$.

Table 1: Comparison of S. FSH, S.LH and S.Estradiol in early perimenopause and AUB group.

\begin{tabular}{|llll|}
\hline Variable & Early perimenopause (median) & Abnormal perimenopausal bleeding (median) & p value \\
\hline FSH & 15.23 & 7.2 & 0.017 \\
\hline LH & 29.30 & 7.6 & 0.008 \\
\hline Estradiol & 27.4 & 29.44 & 1.000 \\
\hline
\end{tabular}

Table 2: Comparison of S.FSH, S.LH and S.Estradiol in late perimenopause and AUB group.

\begin{tabular}{|llll|}
\hline Variable & Late perimenopause (median) & Abnormal perimenopausal bleeding (median) & p value \\
\hline FSH & 31.2 & 7.2 & 0.000 \\
\hline LH & 18.2 & 7.6 & 0.000 \\
\hline Estradiol & 17.8 & 29.44 & 0.015 \\
\hline
\end{tabular}

Majority of women in all groups were multiparous (para $2-4), 76 \%, 73 \%, 70 \%$ respectively.

Frequency of symptoms namely vasomotor changes (hot flashes, flushing, sweating), 60\%; mood changes (depression, anxiety), 32\%; sleep changes (insomnia), $36 \%$; cognitive changes (poor memory, forgetfulness), $36 \%$; vaginal dryness, $16 \%$; was maximum in early perimenopause.

Overall vasomotor changes were the most common symptoms encountered in women in the perimenopausal age group and vaginal dryness the least common in all three groups.

Median values of LH, FSH and estradiol were taken as the values were not normally distributed throughout the groups and hence the mean value would have been skewed.

The median value of $\mathrm{LH}$ in early and late perimenopausal groups was $15.23 \mathrm{IU} / \mathrm{L}$ and $18.2 \mathrm{IU} / \mathrm{L}$ respectively.

The median value of FSH in early and late perimenopausal groups was 29.3IU/L and 31.2IU/L respectively. The median FSH value in early and late perimenopausal group was found to be in the menopausal range ie FSH > 20IU/L and the median of LH in early and late perimenopausal groups was found to be in the normal premenopausal range ie $\mathrm{LH}<30 \mathrm{IU} / \mathrm{L}$.

The levels of LH and FSH in the abnormal perimenopausal bleeding group ranged from premenopausal to post menopausal ranges; median for LH- 7.6IU/L (minimum and maximum being $0.2 \mathrm{IU} / \mathrm{L}$ and 46.7IU/L respectively for $\mathrm{LH}$ ). Whereas the median for FSH-7.2IU/L (minimum and maximum values being $0.8 \mathrm{IU} / \mathrm{L}$ and $99.3 \mathrm{IU} / \mathrm{L}$ respectively for FSH.) Signifying that women in this group may or may not be perimenopausal. Since the interquartile range for $\mathrm{LH}$ and FSH was 3.4-15.2 and 4.4-23.2 most of the women in this group were not perimenopausal. Hence hormonal levels would be more useful than the menstrual characteristics of irregularity and infrequent cycles in these women to label them as perimenopausal.

The median value of estradiol in early perimenopause was $27.4 \mathrm{pg} / \mathrm{ml}$ with an IQR of $11.7-42.8$. The median value of estradiol in late perimenopause was $17.8 \mathrm{pg} / \mathrm{ml}$ with an IQR of 11.6-31.9. These values were in the postmenopausal ranges and signify the decrease in the ovarian function with age. The median value of estradiol in the abnormal perimenopausal bleeding group was $29.44 \mathrm{ng} / \mathrm{ml}$ with IQR of $14.62-41.91$. The $\mathrm{p}$ value between late perimenopause and AUB was 0.015 which was statistically significant.

Tests of significance were applied between the three groups of early and late perimenopause and abnormal perimenopausal bleeding to see if the difference between LH, FSH and estradiol was statistically significant between these groups. Kruskal Wallis $\mathrm{H}$ test detected significant difference between three groups. Further Mann Whitney U test was applied which showed statistically significant difference in FSH between early perimenopause and AUB $\mathrm{p}=0.017$ and $\mathrm{LH}$ between early perimenopause and aub $\mathrm{p}=0.008$. No significant difference was found in estradiol between these two groups. $\mathrm{p}=0.377$. Statistically significant difference was also seen in FSH between late perimenopause and AUB $\mathrm{p}=0.000$, in $\mathrm{LH}$ between late perimenopause and AUB $\mathrm{p}=0.000$ and also in estradiol $\mathrm{p}=0.015$

No statistical significance in FSH, LH and estradiol values was observed between early and late perimenopausal groups. P value being 1.00 for $\mathrm{LH}$ and 
FSH and 0.377 for estradiol. Signifying that there was a comparative rise in the gonadotropin values from early to late perimenopause and decline in estradiol values but this change was not statistically significant.

Table 3: Comparison of S.FSH, S.LH and S.Estradiol in early perimenopause and late perimenopause.

\begin{tabular}{|llll|}
\hline Variable & Early perimenopause (median) & Late perimenopause (median) & p value \\
\hline FSH & 29.3 & 31.2 & 1.00 \\
\hline LH & 15.23 & 18.2 & 1.00 \\
\hline Estradiol & 27.4 & 17.8 & 0.377 \\
\hline
\end{tabular}

Table 4: Comparison of endometrial thickness in early and late perimenopause.

\begin{tabular}{|llll|}
\hline Variable & Early perimenopause & Late perimenopause & p value \\
\hline ET (mean) & 5.48 & 6.13 & 0.851 \\
\hline & Ealy perimenopause & Abnormal perimenopausal bleeding & p value \\
\hline ET (mean) & 5.48 & 7.49 & 0.012 \\
\hline & Late perimenopause & Abnormal perimenopausal bleeding & p value \\
\hline ET (mean) & 6.13 & 7.49 & 0.030 \\
\hline
\end{tabular}

The mean ET in early perimenopause was $5.48 \mathrm{~mm}$ with SD 3.0. In late perimenopause the mean ET was 6.13 with SD 3.32. There was no statistically significant difference between these two groups $p=0.851$.

One case of simple hyperplasia was seen in the late perimenopausal group where the ET was $14 \mathrm{~mm}$. Estradiol level was $23.6 \mathrm{pg} / \mathrm{ml}$ for this patient.

The mean ET in perimenopausal bleeding group was 7.49 with SD 3.78. Significant difference was observed between ET in early perimenopause and aub $(\mathrm{p}=0.012)$ and between late perimenopause and aub $(\mathrm{p}=0.03)$

The difference between ET in early and late perimenopausal groups was not significant $(\mathrm{p}=0.851)$

12 out of 65 abnormal uterine bleeding cases had hyperplastic endometrium after Dilatation and Curettage was done (18.4\%). The mean age of all subjects was 45.33 \pm 6.31 . Mean BMI was $26.9 \pm 6.3 \mathrm{~kg} / \mathrm{m}^{2}$ and mean ET was $12.35 \pm 3.17$. Mean values of LH, FSH and estradiol were $14.2 \pm 10.8 \mathrm{IU} / \mathrm{L}, 9.8 \pm 8.8 \mathrm{IU} / \mathrm{L}, 24.8 \pm 13.2 \mathrm{pg} / \mathrm{ml}$.

The most common type of endometrium $(n=65)$ observed was proliferative endometrium $(41.5 \%)$ other types of endometrium seen after endometrial sampling were secretory $(30.7 \%)$, hyperplastic $(18.4 \%)$, basal (3\%), nonsecretory $(3 \%)$, disordered proliferative $(1.5 \%)$.

\section{DISCUSSION}

This study was a comparative evaluation comprising of 200 women of age above 40 years belonging to the east Delhi population conducted in GTB Hospital. Out of 200 women, 100 fulfilled the criteria of early menopause $(\mathrm{n}=25)$ and late perimenopause $(\mathrm{n}=75)$ as defined by STRAW classification. The other 100 women were experiencing abnormal uterine bleeding. FSH, LH and estradiol were measured irrespective of the day of the cycle as most of them have irregular and heavy menstrual bleeding. A TVS was done in all these women to measure the endometrial thickness. The women who has ET>8 underwent endometrial sampling to rule out endometrial hyperplasia/cancer.

In this study the mean age of all cases ranged from 42-45 years. Maximum women belonged to the lower and upper middle socioeconomic class according to the modified Kuppuswamy scale. ${ }^{9}$

The mean age of women having normal perimenopause belonging to the lower socioeconomic status was $43.17 \pm 4.02$ years, when compared with the overall mean age of patients in normal perimenopause age group $(43.46 \pm 3.90)$ it was found to be slightly lower. Similar observations were made by studies that show that lower socioeconomic status is associated with an earlier age of menopause. On comparing specific markers of SES, both higher education and adult occupational status are associated with higher age at menopause. It is proposed that SES influence on age of menopause may be through factors such as smoking, BMI, psychological stressors, and nutrition.

The mean BMI of women from early to late perimenopause showed an increase, although the increase was not statistically significant $(p=0.506)$. This is consistent with studies that show that menopausal transition is associated with an accelerated decrease in muscle mass and strength as well as an increase in body weight and fat redistribution favoring visceral adiposity (sarcopenic obesity). The menopausal decline in estrogen 
levels is implicated for the change in body composition. ${ }^{10}$ Sarcopenic obesity increases the risk of non communicable diseases (NCD) like cardio-metabolic disorders. ${ }^{11,12}$

Epidemiologic and clinical studies have documented that the process of reproductive aging, although influenced by demographic factors, lifestyle, and BMI, follows a robust and predictable pattern. ${ }^{13-18}$ Although, smoking and BMI influence hormonal levels and the timing of transition, these factors do not alter the trajectory of change in bleeding patterns or hormonal levels with reproductive aging. Therefore, the STRAW +10 staging system is applicable to women regardless of age, demographic, BMI, or lifestyle characteristics. ${ }^{5}$

In the present study most common clinical symptom was vasomotor symptoms in all the groups however it was more frequent in early perimenopause when the hormones a most fluctuant.

On measuring LH, FSH and estradiol it was found that median values of FSH in early and late perimenopause being $29.3 \mathrm{IU} / \mathrm{L}$ and $31.2 \mathrm{IU} / \mathrm{L}$ respectively were in the menopausal range. (>20 IU/L). Whereas median values of LH in early and late perimenopause were in normal premenopausal range $<30 \mathrm{IU} / \mathrm{L}$. When $\mathrm{FSH}$ and $\mathrm{LH}$ were compared between early and late perimenopause it was seen that the levels were higher in late perimenopause although the increase was not statistically significant $(\mathrm{p}=1.00$ each), depicting a declining ovarian reserve.

In the normal perimenopause group there were 16 (out of 100) subjects with high FSH levels and very low estradiol levels. Out of these 9 had clinical symptoms like vasomotor changes, mood symptoms etc. This meant that besides menstrual characteristics we can correlate clinical symptoms with raised FSH and low Estradiol values in $50 \%$ patients in late perimenopause. These women can be picked up to foresee future post menopausal problems and provide preventive therapy.

The levels of LH and FSH in abnormal perimenopausal bleeding ranged from pre to post menopausal ranges. However the median for LH was 7.6 IU/L and for FSH was $7.2 \mathrm{IU} / \mathrm{L}$, the interquartile ranges for $\mathrm{LH}$ and $\mathrm{FSH}$ were 3.4-15.2 and 4.4-23.2 respectively, most of the women in this group were not perimenopausal. Hence hormonal levels would be more useful than the menstrual characteristics of irregularity and infrequency in cycles to label them as perimenopausal.

The median values of estradiol in early and late perimenopause were $27.4 \mathrm{pg} / \mathrm{ml}$ and $17.8 \mathrm{pg} / \mathrm{ml}$ respectively whereas in abnormal perimenopause it was higher $29.4 \mathrm{pg} / \mathrm{ml} \quad(\mathrm{p}=0.015)$. These women with abnormal bleeding tend to have higher estradiol levels and may not be in the perimenopause phase.
The results of LH and FSH coincide with other studies conducted in perimenopasual age groups which showed that postmenopausal levels of FSH(>20IU/L) can be seen despite continued menstrual bleeding while LH levels still remain in the normal range.

The increase in FSH is more than that in LH. Elevated levels of both FSH and $\mathrm{LH}$ are conclusive evidence of ovarian failure. FSH levels are higher than $\mathrm{LH}$ as $\mathrm{LH}$ is cleared from the blood much faster(initial half lives are about 20 minutes for $\mathrm{LH}$ and 3-4 hours for $\mathrm{FSH}$, and perhaps because there is not specific negative feedback peptide for LH like inhibin. ${ }^{20}$

The ReSTAGE collaboration has found that FSH levels of $40 \mathrm{IU} / 1$ or more are indicative of the late menopausal transition, although they are not as strong a predictor as amenorrhea of 60 days or more. ${ }^{20}$

In the present study FSH >40IU/L were found in 18 out of 75 late perimenopausal patients $(24 \%)$.

The median values of estradiol are in the postmenopausal range $(10-20 \mathrm{pg} / \mathrm{ml})$ and decline from early to late perimenopausal groups which could be explained by the declining follicular reserve and the depletion of steriodogenic ovarian tissue with approaching menopause. The low estrogen values in this study could be explained by the fact that the blood samples have not have been drawn around the ovulatory/peak phase as these women had irregular menses. Also some women may be having anovulatory cycles resulting in lower estradiol levels. Some studies have observed both rising and declining levels of estradol as seen in the present study. ${ }^{21,22}$

Women with abnormal perimenopausal bleeding had premenopausal FSH and LH levels. STRAW criteria of menstrual changes cannot be applied to these women hence hormonal level estimation may be more useful to classify these women under perimneopause.

The mean ET in early, late and abnormal perimenopause was $5.48,6.13$ and $7.49 \mathrm{~mm}$ respectively. There was significant statistical difference between ETs in early and abnormal perimenopause, and between ETs in late and abnormal perimenopause. $(\mathrm{p}=0.012$ and $\mathrm{p}=0.03$ respectively). Most common histopathology was proliferative endometrium. This is consistent with many studies. . $^{21,23,24}$

On further analysis of abnormal bleeding cases it was found that 12 cases had hyperplastic endometrium. Mean age of these cases was $45.3 \pm 6.3$, mean BMI was $26.9 \pm 6.3$ $\mathrm{kg} / \mathrm{m}^{2}$. Mean ET was $12.35 \mathrm{~mm}$.

\section{CONCLUSION}

A significant difference was seen in median $\mathrm{FSH}$ and $\mathrm{LH}$ values between normal and abnormal perimenopause. $\mathrm{P}$ 
value for FSH and $\mathrm{LH}$ being 0.017 and 0.008 on comparing early and abnormal perimenopause respectively. Between late and abnormal perimenopause the $\mathrm{p}$ values of FSH and LH were 0.000 each showing statistical significance. There was no statistically significant difference in hormonal levels between early and late perimenopause in the present study.

Median values of estradiol showed a significant difference between late and abnormal perimenopause $\mathrm{p}=0.015$. No significant difference was seen between early and late and early and abnormal perimenopause.

Although, LH and FSH showed a rising trend and estradiol a declining trend as women progressed in their menopausal transition from early to late perimenopause implying a continuous decrease in ovarian follicular reserve with progression of STRAW stage.

Clinical symptoms like somatic, psychological and genitourinary problems were most common in early perimenopause although there was no significant difference between early and late perimenopause.

Most of the women with abnormal bleeding had LH and FSH in the premenopausal range, this might denote that till there is heavy menstrual bleeding, normal perimenopause has not set it.

The most common histopathological finding seen in abnormal perimenopausal bleeding $(n=65)$ was proliferative endometrium (41.5\%).

Endometrial hyperplasia was seen in $18.4 \%$ patients $(n=65)$.

Funding: No funding sources

Conflict of interest: None declared

Ethical approval: The study was approved by the Institutional Ethics Committee

\section{REFERENCES}

1. World Health Organization Research on the Menopause in the 90s. Technical Report Ser 866, Geneva, Switzerland: World Health Organization; 1996.

2. McKinlay SM, Brambilla DJ, Posner JG. The normal menopausal transition. Maturitas. 1992;14:103-15.

3. Gupta B, Goel N, Sharma G. Symptoms and Signs. Menopause In Eds Goel N Gupta B Jaypee Brothers Med Publishers P Ltd, Delhi; 2014:27-36.

4. Burger HG, Hale GE, Dennerstein L. Cycle and hormone changes during perimenopause: the key role of ovarian function. Menopause. 2008;15:603-12.

5. Harlow SD, Gass M, Hall JE. STRAW + 10 collaborative group. Executive summary of the stages of reproductive aging workshop +10 : addressing the unfinished agenda of staging reproductive aging. J Clin Endocrinol Metab. 2012;97(4):1159-68.

6. Petsos P, Buckler H, Mamtora H, Anderson D. Ovulation after treatment with ethinyl estradiol and medroxprogesterone acetate in a woman approaching premature menopause. $\mathrm{Br} \mathrm{J}$ Obstet Gynaecol. 1986;93:1155-60.

7. Brambilla DJ, McKinlay SM, Johannes CB. Defining the perimenopause for application in epidemiologic investigations. Am J Epidemiol. 1994;140(12):10915.

8. Hale GE, Hughes CL, Burger HG, Robertson DM, Fraser IS. Atypical estradiol secretion and ovulation patterns caused by luteal out-of-phase (LOOP) events underlying irregular ovulatory menstrual cycles in the menopausal transition. Menopause. 2009;16:50-9.

9. Kuppuswamy B. Manual of socioeconomic status (urban). Delhi: Manasayan; 1981.

10. Vaidya R, Shah M, Vaidya A. Menopausal transition: a signal to prevent and offset sarcopenic obesity. In eds Goel N, Gupta B Menopause Jaypee Brothers Med Publishers P Ltd, Delhi; 2014:177-8.

11. Cesari M, Kritchevsky SB, Baumgartner RN. Sarcopenia, obesity and inflammation- results from the trial of Angiotensin Converting Enzyme Inhibition and Novel Cardiovascular Risk Factors study. Am J Clin Nutr. 2005;82:428-34.

12. Peppa M, Koliaki C, Dimitriadis G. Body composition as an important determinant of metabolic syndrome in postmenopausal women. Endocrinol Metabol Syndrome. 2012;S1:009.

13. Miles TP, Bernard MA, Morbidity, disability, and health status of black American elderly: a new look at the oldest-old. J Am Geriatr Soc. 1992;40:1047.

14. Day JC. Bureau of the Census, Current population reports. Population projections of the United States, by age, sex, race, and Hispanic origin: 1993 to 2050, U.S. Government Printing Office, Washington, D.C. 1993.

15. Fries JF, The sunny side of aging. JAMA. 1990;263:2354.

16. Fries JF. Strategies for reduction of morbidity. Am J Clin Nutr. 1992;55:1257S.

17. Vollman RF. The menstrual cycle, In: Friedman E, ed. Major Problems in Obstetrics and Gynecology, W.B. Saunders Co., Philadelphia; 1977.

18. Klein NA, Harper AJ, Houmard BS, Sluss PM, Soules MR. Is the short follicular phase in older women secondary to advanced or accelerated dominant follicle development? J Clin Endocrinol Metab. 2002;87:5746.

19. Spearoff L, Fritz MA. Menopause and the perimenopausal transition. Clin Gyne Endocrinol Infert. 2010:689.

20. Randolph JF, Crawford S, Dennerstein L. The value of follicle-stimulating hormone concentration and clinical findings as markers of the late menopausal transition. J Clin Endocrinol Metab. 1992;91(8):3034-40. 
21. Prior JC. Perimenopause: the complex endocrinology of the menopausal transition. Endocr Rev. 1998; 19:397-428.

22. Burger HG, Dudley EC, Hopper JL. Prospectively measured levels of follicle stimulating hormone, oestradiol and the dymeric inhibins during the menopausal transition in a population based cohort of women. J Clin Endocrinol Metab. 1999;84:402530

23. Shobha S. Pillai Sonographic and histopathological correlation and evaluation of endometrium in perimenopausal women with abnormal uterine bleeding. Int J Reprod Contracept Obstet Gynecol. 2014;3(1):113-7.

24. Jetley S, Rana S, Jairajpuri ZS. Morphological spectrum of endometrial pathology in middle aged women with atypical uterine bleeding - a study of 219 cases. J Midlife Health. 2013;4:216-20.

Cite this article as: Kaur H, Goel N. Comparative evaluation of menstrual patterns and hormonal profiles in normal and abnormal perimenopause. Int J Reprod Contracept Obstet Gynecol 2019;8:3556-63. 